\title{
Democracia y Corte Interamericana de Derechos Humanos: Participación, oposición y acceso a la justicia ${ }^{1}$
}

\section{Democracy and The Inter-American Court of Human Rights: Participation, Opposition and Access to Justice}

\author{
Alejandro Sahuí ${ }^{2}$ \\ Universidad Autónoma de Campeche (México) \\ ORCID: https://orcid.org/0000-0003-1823-1459
}

Recibido: 10-12-2019

Aprobado: 16-07-2020

\section{Resumen}

El texto propone una guía para comprender la idea de democracia subyacente en el Sistema Interamericano de Derechos Humanos. Con base en la noción de poliarquía de Robert Dahl se destacan los principios de participación y oposición. Ambos revelan los ascendientes igualitario y liberal de la democracia que deben orientar la actividad interpretativa de la Corte IDH, más allá de que se traten específicamente casos de derechos políticos. El propósito es visibilizar el ineludible rol público-político de los tribunales. Ello implica revisar la calidad de sus razones, la corrección de sus procedimientos de justificación, y la naturaleza de su autoridad. Por el carácter de la función judicial, se analiza la idea de democracia en conjunción con el derecho humano de acceso a la justicia.

Palabras-clave: democracia, tribunales, acceso a la justicia, participación, oposición.

\footnotetext{
${ }^{1}$ Este artículo se ha realizado en el marco del proyecto de investigación "Teorías de la justicia y derecho global de los derechos humanos" (referencia PID2019-107172RB-I00), financiado por el Ministerio de Ciencia e Innovación de España.

2 (alesahui@uacam.mx) Fue director de la Facultad de Derecho y director del Centro de Investigaciones Jurídicas de la Universidad Autónoma de Campeche. Actualmente es profesor investigador en la misma Universidad. Miembro del sistema nacional de investigadores del CONACYT nivel 2. Entre sus libros destacan: Igualdad y calidad de la democracia (México: Fontamara, 2018); Igualmente libres. Pobreza, justicia y capacidades (México: Ediciones Coyoacán/FLASUD, 2009); Razón y espacio público. Arendt, Habermas y Rawls (México: Ediciones Coyoacán, 2002, 2009).
} 


\begin{abstract}
The paper proposes a guide to understand the idea of democracy that underlies the Inter-American Human Rights System. Based on the notion of polyarchy from Robert Dahl it highlights the principles of participation and opposition. Both reveal the egalitarian and liberal ascendancy of democracy that should orient the interpretive activity of the Inter-American Court of Human Rights, independently it refers to cases related with political rights. The main purpose is to make visible the inescapable public-political role of the courts. This implies reviewing the quality of their reasons, the correctness of their justification procedures, and the nature of its authority. Due to the nature of the judicial function, the idea of democracy is revisited together with the human right of access to justice.
\end{abstract}

Key-words: Democracy, Courts, Access to Justice, Participation, Opposition.

\title{
Introducción
}

El texto reflexiona sobre la relación existente entre la democracia y la Corte Interamericana de Derechos Humanos (Corte IDH). Esta relación trasciende las decisiones sobre casos directamente asociados con derechos políticos, ya que los criterios de interpretación incluidos en el artículo 29 del Pacto de San José, obligan a una hermenéutica integral.

Resulta conveniente indagar por los alcances prácticos de la noción de democracia sostenida por la Corte IDH. De acuerdo con los instrumentos normativos que la enmarcan, esta idea de democracia se adscribe al modelo de democracia liberal, por su relación con las libertades de expresión, reunión, asociación o petición.

En este trabajo no solamente se revisan asuntos relacionados con derechos políticos, sino también con derechos civiles o derechos culturales, como la consulta previa a personas, pueblos y comunidades indígenas. En estos otros casos lo relevante no sería la sustancia inmediata del reclamo, sino que existan instrumentos accesibles, oportunos y eficaces para hacerlo público y para forzar una respuesta de las autoridades. Esta es la dimensión política que se pretende destacar.

El texto propone una ruta para interpretar la noción de democracia en el sistema interamericano de protección de derechos humanos. Bajo la guía de Robert Dahl se destaca un par de atributos que hacen de la democracia un régimen que aventaja al resto debido a su legitimidad: su capacidad de incluir la participación del mayor número, lo que refleja su dimensión igualitaria; y su capacidad de promover la expresión plural de la oposición, lo que refleja su 
dimensión liberal ${ }^{3}$. El propósito es visibilizar el papel político de la Corte: su responsabilidad en relación con el régimen democrático. Ello implica revisar la calidad de sus razones, la corrección de sus procedimientos de justificación, y la naturaleza de la autoridad (autoritativa, epistémica) con que pretenden investirlas.

Se analiza la idea de democracia en conjunción con el derecho humano de acceso a la justicia o tutela judicial efectiva. Este derecho es interpretado en clave democrática ${ }^{4}$. A pesar de que se interpreta comúnmente como un derecho de naturaleza civil, en realidad no es un derecho que se pueda disfrutar de modo pasivo, porque funciona siempre como un poder ${ }^{5}$ : otorga a las personas un estatus en relación con los demás y enfrente de los órganos del Estado. En términos prácticos, el acceso a la justicia funciona como derecho "llave" porque abre la puerta a cualesquiera de las pretensiones personales ${ }^{6}$. Éstas tendrán que ser vistas, escuchadas y atendidas, aunque luego sean rechazadas; y esta es una cuestión atinente tanto a los derechos como a la misma democracia.

La primera parte señala los rasgos principales del modelo de democracia representativa de la Carta de la OEA y la CDI. Estos son interpretados a partir de la concepción de democracia poliárquica de Robert Dahl, que destaca el pluralismo y que propone dos principios para comprender y evaluar a las democracias: participación y oposición.

En la segunda parte se señala el papel de la Corte IDH en la garantía de la democracia. Su importancia no se deduce sólo de los límites negativos que se pueda oponer a las amenazas y los abusos del poder, en el sentido defensivo del constitucionalismo liberal y su conocida fórmula de división de poderes, de los frenos y los contrapesos. Lo que se propone es que ese papel se entiende mejor por su capacidad de asegurar la igualdad de oportunidades en la competencia política y de activar instancias incluyentes para quienes están permanentemente fuera por ser opositores radicales ${ }^{7}$.

\footnotetext{
${ }^{3}$ Robert Dahl, La poliarquía. Participación y oposición, Madrid, Tecnos, 1989.

4 "[El acceso a la justicia] se erige como pilar fundamental de un Estado democrático y se constituye como una obligación de los Estados partes, de manera que los Estados tienen el deber de poner a disposición de sus ciudadanos mecanismos y recursos judiciales accesible, eficaces y adecuados", Alfredo Islas-Colín y Alejandra Díaz Alvarado, "El derecho de acceso a la justicia en el Sistema Interamericano de Protección de Derechos Humanos: construcción doctrinal y jurisprudencial", Prospectiva jurídica, México, UAEM, año 7, número 14, julio-diciembre 2016, p. 47.

5 Si uno atiende a la clasificación de Luigi Ferrajoli sobre los derechos fundamentales, el derecho de acceso a la justicia no sería en estricto sentido un derecho primario o sustancial, sino secundario, instrumental o de autonomía. Luigi Ferrajoli, Los fundamentos de los derechos fundamentales, Madrid, Trotta, 2001, pp. 22-23.

6 Señala Cançado Trindade: el acceso a la justica es "un verdadero derecho al Derecho", en "El derecho de acceso a la justicia internacional y las condiciones para su realización en el sistema interamericano de protección de los derechos humanos", Revista IIDH, vol. 37, 2003, pp. 72-73.

${ }^{7} \mathrm{La}$ forma en que los regímenes políticos tratan a los desobedientes políticos radicales dice mucho acerca de la calidad de un sistema democrático. Al respecto, Jürgen Habermas, "La desobediencia civil. Piedra de toque del Estado democrático de derecho", Ensayos políticos, Barcelona, Península, 2000, pp. 51-71.
} 
La tercera y cuarta secciones pasan revista panorámica a unos pocos casos de la Corte relacionados con el régimen político y las instituciones democráticas. La tercera analiza un par de asuntos sobre derechos políticos, sistema electoral, candidaturas y partidos; y luego en la cuarta se miran unos pocos más relativos a las libertades de expresión, manifestación o reunión. Aunque esta revisión dista mucho de ser exhaustiva, acredita un tipo de criterios para apreciar los principios y valores que los jueces de la Corte imputan a la democracia.

En la medida que esta idea de democracia sea clarificada y afianzada en la jurisprudencia de la Corte IDH, cabría esperar que la ventaja de amplificar las voces de todas las personas y de garantizar el mismo peso a su participación contribuyan a hacer eficaz el catálogo integral de derechos humanos. A tratar de justificar esta afirmación se dedica la quinta parte, que destaca la prioridad práctica de los derechos políticos y del acceso a la justicia en clave democrática: como paridad participativa.

En este propósito se revisan casos que no son relativos a cuestiones políticas de modo directo, pero que podrían ser reinterpretados a la luz de este enfoque. Al hablar de la prioridad práctica de los derechos políticos se quiere destacar la funcionalidad heurística del acceso a la justicia, su papel instrumental, pragmático y público. El estatuto de agentes que reclaman es lo que se pone por delante cada vez, antes que la materia de lo reclamado, así como el deber de responder con razones todas y cada una de las demandas expuestas.

Se concluye que la idea de participación incluyente, por igualitaria y plural, por liberal; junto con el acceso a la justicia, auxilia a comprender el sentido específicamente político de las demandas al sistema de los derechos más allá del régimen democrático (sistema electoral, partidos, representación, etc.). A través de cualquier reclamo elevado a un tribunal por un grupo o un individuo débiles, las autoridades están forzadas a justificarse. Esto quiere decir que en las democracias con instrumentos de control judicial se favorece mayores participación y oposición. Con estos mecanismos procesales todas las posiciones políticas, por insulares y modestas que sean, están en aptitud de controvertir decisiones mayoritarias que por los canales normales de la representación sería imposible. De ahí la importancia del acceso a la justicia. En una democracia liberal ciudadanas y ciudadanos se conciben a sí mismos "como fuentes autoautentificatorias de exigencias válidas".

${ }^{8}$ John Rawls, La justicia como equidad. Una reformulación, Barcelona, Paidós, 2002, p. 48. La idea liberal de legitimidad en un sentido similar está presente en Armin von Bogdandy e Ingo Venzke, ¿En nombre de quién? Una teoría del derecho público sobre la actividad judicial internacional, Bogotá, Universidad Externado de Colombia, 2016. 


\section{La democracia representativa y liberal en el Sistema Interamericano}

Sostiene Pedro Nikken que la democracia representativa ha sido designada acertadamente por la Corte IDH como "un 'principio' reafirmado por los Estados americanos en la Carta de la OEA, instrumento fundamental del Sistema Interamericano" ". Es interesante el impulso al tratamiento de la democracia representativa dentro del sistema inspirado en gran medida por las transformaciones y transiciones políticas de la región en el último tramo del siglo XX, la "tercera ola democratizadora", que fue afirmada con un fuerte compromiso estatal en 1991 mediante la Resolución 1080, misma que versa de manera específica sobre la democracia representativa ${ }^{10}$.

No existe empero una definición explícita de la democracia representativa ni en la Carta de la OEA ni en la Carta Democrática Interamericana (en adelante CDI). Pedro Nikken propone interpretarla integralmente con el artículo XX de la Declaración Americana de los Derechos y Deberes del Hombre como "aquella forma de gobierno que emana del pueblo a través de representantes elegidos mediante elecciones populares, de voto secreto, genuinas, periódicas y libres".

Pese a no ofrecer una definición estricta como tal, la CDI contempla ciertos elementos esenciales y componentes fundamentales de la democracia representativa:

Artículo 3. Son elementos esenciales de la democracia representativa, entre otros, el respeto a los derechos humanos y las libertades fundamentales; el acceso al poder y su ejercicio con sujeción al estado de derecho; la celebración de elecciones periódicas, libres, justas y basadas en el sufragio universal y secreto como expresión de la soberanía del pueblo; el régimen plural de partidos y organizaciones políticas; y la separación e independencia de los poderes públicos.

Artículo 4. Son componentes fundamentales del ejercicio de la democracia la transparencia de las actividades gubernamentales, la probidad, la responsabilidad de los gobiernos en la gestión pública, el respeto por los derechos sociales y la libertad de expresión y de prensa.

Estos atributos incluidos en la CDI para la noción de democracia representativa se pueden enmarcar dentro del paradigma de la democracia pluralista, entendida por Robert Dahl como poliarquía. Lo relevante de la perspectiva de Dahl es el papel práctico que confiere a los principios de

\footnotetext{
9 Pedro Nikken, "Análisis de las definiciones conceptuales básicas para la aplicación de los mecanismos de defensa colectiva de la democracia previstos en la Carta Democrática Interamericana", Revista IIDH, vol. 43, 2006, p. 18

${ }^{10}$ Sergio Meza Salazar, "La democracia y el Sistema Interamericano: de la Carta de la OEA a la Carta Democrática Interamericana”, Agenda Internacional, Año VII, No. 16, 2002, pp. 97-122.
} 
participación y oposición en la evaluación de las democracias. Cuando éstas no son incluyentes y no admiten la expresión de la disidencia, las democracias pierden legitimidad.

La democracia como fue delineada por Joseph A. Schumpeter consiste en un método "en el que los individuos adquieren el poder de decidir por medio de una lucha de competencia por el voto del pueblo"11. La importancia del modelo está en su naturaleza competitiva pluralista. Por ende, rechaza las concepciones de la democracia que atribuyen al sistema político fines intrínsecos, y es escéptico respecto de expresiones como "pueblo", "bien común" o "voluntad general". No existen fines que condicionen el carácter democrático de regímenes organizados bajo presupuestos procedimentales, siempre que se garantice inclusión y apertura a la competencia; y nadie disponga de autoridad para prejuzgar los intereses que circulen en la esfera pública.

En términos de diseño institucional el modelo pluralista ha adoptado las reglas y procedimientos de la democracia representativa, electiva, dentro de un marco liberal. No obstante, es menester subrayar que existen gran diversidad de pautas para organizar la representación y para gestionar la mayor inclusión. No se puede conocer a priori la capacidad de cada arreglo institucional para traducir los intereses en influencia y poder políticos. Sin embargo, es posible comprender los principios bajo los que dichos arreglos deberán ser enjuiciados. En principio, todos los sujetos políticos deben disponer de la misma capacidad de participar con el mismo peso de la calidad de ciudadanos con libertad de información, expresión o reunión; con iguales derechos políticos de votar y ser votados; con medios de control y de rendición de cuentas.

Con esto en mente cabe discutir cómo se refleja mejor la representación popular en órganos como los parlamentos: mediante criterios territoriales; numéricos según el tamaño de los núcleos de población; con sensibilidad o no al pluralismo ideológico mediante esquemas mayoritarios o de representación proporcional; visibilizando o no las dimensiones étnicas, religiosas, culturales o de género; entre otras tantas posibilidades. Sin embargo, nada puede garantizar a priori la imparcialidad de las normas y de las políticas públicas.

Mauricio Merino llama a pensar la relación entre sistema electoral y régimen político ${ }^{12}$. El sistema electoral contiene las reglas mediante las cuales la ciudadanía puede expresar sus preferencias con votos. En hipótesis, los votos deben transformarse en escaños o en cargos de gobierno. La cuestión es que la forma de contar los votos para distribuir dichos escaños y cargos tiene efectos determinados: más o menos influencia y poder para ciertas personas y grupos. Por ende, el sistema electoral no es un asunto puramente técnico ni

11 Joseph A. Schumpeter, Capitalismo, socialismo y democracia (vols. I y II), Barcelona, Folio, 1996, p. 343.

${ }^{12}$ Mauricio Merino, La transición votada, Ciudad de México, FCE, 2003, p. 46. 
puede ser diseñado ajeno a los valores que proporcionan legitimidad al régimen político. De modo significativo: igualdad y libertad, garantizando sus referentes empíricos, según Dahl: inclusión universal en la participación de la ciudadanía, con el mismo peso (componente igualitario); y garantías para una oposición plural, competitiva e incluso radical (componente liberal).

\section{Democracia representativa, tribunales y acceso a la justicia}

Debido a la imposibilidad de anticipar una equidad plena en el desempeño del régimen político, cabe pensar la responsabilidad de los jueces para revisar caso a caso cómo se aterrizan los principios y los derechos políticos en las democracias de la región. Guillermo O’Donnell cree que no se puede fijar $a$ priori una lista de libertades, derechos y oportunidades que garantice poderes de participación política equivalentes. Por lo tanto, su formulación se realiza inductivamente y mediante juicios hipotéticos y causales susceptibles de control judicial a posteriori, en forma casuística. Cuáles libertades y sus alcances sean condiciones necesarias para una competencia política justa es asunto que depende de juicios de tipo probabilístico: "si dichas condiciones se cumplen, entonces existe, ceteris paribus, alta probabilidad de que las elecciones sean limpias" 13 .

En la CDI se relaciona directamente el régimen político y el sistema de derechos. Su artículo 7 señala que "la democracia es indispensable para el ejercicio efectivo de las libertades fundamentales y los derechos humanos, en su carácter universal, indivisible e interdependiente". Además, es enfática en que el sistema de protección de derechos es el instrumento primordial para cuidar de la democracia.

John Hart Ely ha propuesto que los tribunales son capaces de verificar el cumplimiento de los valores de participación y de inclusión para identificar de manera adecuada opinión pública y la voluntad popular plasmada en una Constitución. Si los jueces supervisan la calidad del proceso democrático su función podría ser interpretada políticamente, como un espacio que amplifica las voces y apuntala ciertas posiciones, en clave democrática. Desde este punto de vista los jueces participan en la esfera de la opinión pública, no autoritativa sino deliberativamente. El acceso a la justicia, en este contexto puede ser leído como institución de la democracia representantiva y pluralista ${ }^{14}$.

La tutela judicial de los derechos moviliza en una instancia peculiar el proceso democrático. En un entorno institucional que no es de naturaleza

${ }^{13}$ Guillermo O'Donnell, Democracia, agencia y estado. Teoría con intención comparativa, Buenos Aires, Prometeo Libros, 2010, p. 34.

${ }^{14}$ John Hart Ely, Democracy and Distrust: A Theory of Judicial Review, Cambridge, Mass., Harvard University Press, 1980, p. 135.

Araucaria. Revista Iberoamericana de Filosofí, Politica, Humanidades y Relaciones Internacionales, año $23, \mathrm{n}^{\circ} 46$. Primer cuatrimestre de 2021. Pp. 461-482. ISSN 1575-6823 e-ISSN 2340-2199 https://dx.doi.org/10.12795/araucaria.2021.i46.23 
mayoritaria pero tampoco anti o contra-democrática. No es correcta, por tanto, la interpretación de esta tutela en el sentido de que a los jueces corresponda defender específicamente a minorías y grupos desaventajados. Les toca más bien garantizar que los derechos humanos de nadie sean atropellados, sean minorías o mayorías.

A personas y grupos en desventaja estructural puede otorgárseles favores procesales y hermenéuticos - ajustes razonables-, pero no a priori la razón de todas sus demandas ${ }^{15}$. Piénsese en la consulta previa a personas, pueblos y comunidades indígenas; y otras ventajas para redistribuir cargas argumentativas y probatorias. Estos instrumentos cumplen una función heurística; su propósito es contribuir a visibilizar las posiciones débiles de personas y grupos excluidos de la conversación pública ${ }^{16}$.

Durante un proceso judicial, debido a mecanismos contradictorios, en los tribunales se defienden razones de minorías como de mayorías políticas sobre asuntos particulares. Tratándose de procesos de carácter adversarial las partes actúan en defensa de determinados intereses que asumen podrían ser justificados en público con los mejores argumentos. Por ende, no es posible prejuzgar quien tenga la razón. Si se mira a la democracia en un continuo, y no en momentos discretos, cabría confiar que ciertos litigios de impacto movilicen la opinión pública y conduzcan a cambiar la correlación de fuerzas políticas. El modelo de democracia representativa puede incluir instancias deliberativas que coadyuven con las instancias de representación abriendo espacios imparciales, reflexivos y plurales para perfeccionar la voluntad popular ${ }^{17}$.

La crisis actual que se imputa a las democracias representativas, liberales y pluralistas ha conducido a proponer instrumentos de democracia directa como referéndum, plebiscito, iniciativa ciudadana, revocación de mandato o consulta popular, mediante los cuales se denuncia el distanciamiento de las élites. El motivo de estos esquemas partipacionista es dar cabida al mayor número de voces para recuperar el poder de la gente. Sin embargo, aunque estos medios sirvan para auscultar la voluntad popular y tratar de devolverle su centralidad, es difícil captar desde ellos la pluralidad de intereses y valores de la opinión pública $^{18}$.

${ }^{15}$ Roberto Saba, Más allá de la igualdad formal ante la ley ¿Qué les debe el Estado a los grupos desaventajados?, Buenos Aires, Siglo XXI, 2016.

${ }^{16}$ Dice Robert Alexy: "Quien consiga convertir en vinculante su interpretación de los derechos fundamentales -esto es, en la práctica, quien logre que sea adoptada por el Tribunal Constitucional Federal-, habrá alcanzado lo inalcanzable a través del procedimiento político usual", en "Los derechos fundamentales en el Estado constitucional democrático", en Miguel Carbonell (ed.), Neoconstitucionalismo(s), Madrid, Trotta, 2009, p. 36.

${ }_{17}$ Sobre esta discusión se puede ver Roberto Gargarella (comp.), Por una justicia dialógica. El Poder Judicial como promotor de la deliberación democrática, Buenos Aires, Siglo XXI, 2014.

18 Sobre algunas dificultades y riesgos de la democracia directa, Alicia Lissidini, Yanina Welp y Daniel Zovatto (comps.), Democracias en movimiento. Mecanismos de democracia directa y participativa en América Latina, Ciudad de México, UNAM, 2014.

Araucaria. Revista Iberoamericana de Filosofia, Politica, Humanidades y Relaciones Internacionales, año $23, \mathrm{n}^{\circ} 46$. Primer cuatrimestre de 2021. Pp. 461-482. ISSN 1575-6823 e-ISSN 2340-2199 https://dx.doi.org/10.12795/araucaria.2021.i46.23 
Los regímenes democráticos podrían disponer múltiples diseños institucionales debido a diferentes condiciones sociales, culturales e históricas; el acomodo relativo de los grupos de interés; el carácter más o menos homogéneo de la población o sus circunstancias geográficas. Bajo la perspectiva que se propone, el acceso a la justicia se concentraría en el control de los procedimientos para asegurar la participación y la oposición de cualquier ciudadano. De ahí la importancia de entender este derecho como una "llave" al espacio de la política: será mejor cuanto más sencilla y llana sea su utilización.

En consecuencia, a pesar del aparente optimismo de señalar esta función trascendente de tribunales y cortes en la garantía de los derechos humanos y la democracia, no existen en la actualidad condiciones efectivas ni equitativas de acceso a la justicia. Las personas y los grupos excluidos suelen carecer de oportunidades para demandar esa garantía de tutela ante la judicatura. Los órganos del poder judicial han sido denunciados permanentemente por su alejamiento de la gente y por lo difícil y oneroso que resulta recurrir ante ella. Si en el ámbito nacional dicho acceso es una aventura incierta, se puede imaginar cómo resulte alcanzar a la Corte IDH.

\section{Corte IDH, derechos políticos y democracia representativa}

En la región los derechos políticos se encuentran establecidos en el artículo 23 de la Convención Americana sobre Derechos Humanos. Si se mira esta categoría de derechos en conjunto con la libertad de conciencia y de religión; libertad de pensamiento y expresión; derecho de reunión; y libertad de asociación, se constata el espíritu liberal de la Convención, sobre cuyos fundamentos normativos se asienta el trabajo de la Corte IDH. Este tipo de libertades civiles brindan una pauta para entender la política en contextos de pluralidad y participación incluyente. El pluralismo parece tener su mejor aterrizaje institucional en esquemas de democracia representativa, ya que un propósito principal de este modelo consiste en hacer oir las pretensiones de todas las personas, sin olvidar que su naturaleza es diversa, fraccionaria, heterogénea.

Con este sentido la CDI interpreta el perfil institucional de nuestras democracias: la justicia social y la igualdad son inherentes a la democracia y los derechos económicos, sociales y culturales deben ser "reafirmados, desarrollados, perfeccionados y protegidos en función de consolidar el régimen democrático representativo de gobierno". La Carta pone énfasis en el carácter participativo del sistema político y destaca el deber de garantizar el ejercicio efectivo de la democracia representativa. 
La efectividad de los derechos políticos, su dimensión material, es destacada por la Convención. El artículo 23 señala que la ciudadanía debe gozar los derechos políticos, pero no sólo de modo declarativo, sino además de oportunidades reales para ejercerlos. Los derechos políticos son la única categoría de derechos humanos donde se vincula la idea de derechos esencialmente con las iguales oportunidades.

John Roemer indica que la noción de igualdad de oportunidades no debe reducirse a la simple idea de no discriminación ante las leyes; es decir, no debe acotarse al idéntico trato al momento del acceso a la competencia pública por bienes y derechos ${ }^{19}$. La igualdad de oportunidades implica nivelar el campo de juego para individuos y colectivos. Ello exige visibilizar las condiciones desiguales de la competencia política, desagregando a los grupos sociales a partir de sus desventajas comparativas; sobre todo de aquellas que suelen ser reiteradas, históricas e injustificadas.

Esta asociación entre derechos políticos e iguales oportunidades llama la atención, porque ni siquiera en el caso de los derechos económicos, sociales y culturales, se vincula intrínsecamente su garantía efectiva con tener las mismas oportunidades. En los DESC es suficiente con el hecho de que se indique la progresión hacia su cumplimiento como se consigna en el artículo 26 de la Convención.

Esto implica que en los casos relativos a derechos políticos, la obligación de reparar las desventajas económicas, sociales y culturales es directa e inmediata, porque este tipo de derechos sufre una lesión y es violado en el instante que las personas no cuentan con las mismas oportunidades para hacerlos efectivos de un modo realista y verosímil. No basta que las personas puedan ingresar a la competencia política si esta es inequitativa.

El régimen democrático debe idear reglas y procedimientos con oportunidades semejantes para todos, y debe hacerlo de forma inmediata, no progresiva, ni limitándose a los recursos que tenga a su alcance. Si se descubre inequidad en la competencia, los tribunales deben ordenar el cumplimiento inmediato de los derechos, aunque las medidas traten cuestiones económicas, sociales o culturales. La igualdad en derechos políticos exige paridad participativa y esta exige satisfacer metas sustantivas allende la igualdad formal. El financiamiento público de partidos; la prohibición de contratar publicidad en las campañas; la paridad de género; las cuotas de minorías; y algunos mecanismos de veto o de consulta previa, son medios de igualación material, de nivelación de las oportunidades.

Para Roberto Cuéllar M. y José Thompson la igualdad de oportunidades comprendida en este contexto no persigue maximizar los derechos de los grupos desaventajados en sentido distributivo, de justicia social. La cuestión es

19 John Roemer, Equality of Opportunity, Cambridge, Harvard University Press, 1998. 
política y pretende establecer "un leveled playing field, donde lo que interesa es crear las condiciones para tener una oportunidad igualitaria de participar en la contienda más que compensar condiciones desiguales" ${ }^{20}$.

Este enfoque queda de manifiesto en los dos primeros casos conocidos por la Corte IDH que trataron específicamente sobre derechos políticos; a saber, el Caso Yatama Vs Nicaragua y el caso Castañeda Gutman Vs México. Las respuestas diferentes entrambos se debieron precisamente a oportunidades materiales desiguales para acceder a cargos de elección, de la comunidad Yatama, por un lado, grupo indígena marginal frente al resto de la ciudadanía nicargüense; y de Jorge Castañeda, un influyente personaje en la opinión pública mexicana, por el otro. La supuesta común violación a los derechos políticos alegada por Castañeda se atribuía a discriminación e inequidad en las oportunidades para competir por fuera de organizaciones políticas regulares en Nicaragua y México, respectivamente. Sólo en el caso Yatama la Corte IDH reconoció derechos políticos diferenciados.

Con base en una concepción de la justicia que connota el reconocimiento de la dimensión pluricultural de la comunidad Yatama, amén de sus circunstancias desaventajadas históricas y estructurales, la Corte IDH estimó que la aparente neutralidad de la legislación electoral de Nicaragua producía un resultado discriminatorio, un efecto dispar en los derechos y oportunidades de participar. En cambio, en el caso Castañeda contra México, en la regulación de la competencia a través de partidos políticos, que no admitía concurso de candidaturas independientes, la Corte IDH no acreditó discriminación ni acceso inequitativo a oportunidades.

En el caso de Yatama, la negativa del estado de Nicaragua a admitir sus reclamos ocasionó un ochenta por ciento de abstencionismo electoral en la población total, que no se sintió representada. Según la Corte, las pretensiones de Castañeda y de la comunidad indígena Yatama no son equivalentes, pese a sus semejanzas aparentes. Esta decisión ofrece un significado específico a las ideas de participación y representación equitativas que lleva a interpretar la idea de igualdad política en el sentido pluralista de Robert Dahl. Un enfoque plural que posee un ascendiente liberal, pero que no es individualista, egoísta o atomista -defectos asociados comúnmente con esta doctrina. No toda pretensión particular fortalece la democracia ni mejora su calidad. Sin embargo, los estados deben hacer lo más que puedan para garantizar la expresión de las voces excluidas: los disidentes y opositores más radicales.

La Corte IDH rechaza la igualdad política entendida como mera neutralidad ante las leyes. Reconoce que la Convención no establece un régimen electoral único. Admite que pueda existir amplia variedad de regulaciones, siempre que

\footnotetext{
${ }^{20}$ Roberto Cuéllar M. y José Thompson, "Presentación”, en VVAA, Construyendo las condiciones de equidad en los procesos electorales, Serie Cuadernos de Capel No. 57, San José, IIDH, 2012, p. 9. 
desarrollen elecciones periódicas y auténticas bajo los principios del sufragio universal, libre y secreto. Basta respetar el principio de legalidad y postular un fin legítimo necesario y proporcional; razonable para una democracia pluralista y representativa. En los casos referidos, esto querría decir que las oportunidades para concursar por una candidatura debían ser maximizadas, no ser restrictivas ni discriminatorias. En el caso Castañeda la Corte IDH no juzgó injusto el diseño institucional ni sus consecuencias inequitativas.

Estos fallos se pueden interpretar bajo coordenadas distintas a las concepciones igualitaristas más comunes, ámbito donde ha influido ampliamente la justicia como equidad de John Rawls ${ }^{21}$. Debido a su enfoque redistributivo predominante se reveló pronto múltiples puntos ciegos; de los que surgieron los debates con el feminismo, el racismo, el comunitarismo y el multiculturalismo, el marxismo, o las capacidades humanas. En este trayecto Nancy Fraser señala la naturaleza pluridimensional de la justicia, y complementa ese interés redistributivo con otros temas como el reconocimiento cultural y la representación política.

Con este marco se entienden mejor no sólo casos como Yatama versus Nicaragua, que admite tratos diferenciados en la regulación de la competencia, sino también diversas sentencias en temas de consulta indígena. Por un lado, estas señalan el reconocimiento de la especificidad étnica y cultural, y por el otro, la dimensión de la representación política que subyace regularmente a estos asuntos y suele ser invisibilizada cuando se describen con la pura dinámica de mayorías y minorías. La consulta previa es una herramienta coherente con los principios de la democracia representativa porque su función principal es deliberar acerca de los puntos de vista y reclamos de grupos subrepresentados de modo estructural e histórico; quienes tienen menores oportunidades para competir por la vía política normal.

De modo natural se vinculan pluralismo y liberalismo para enfatizar el deber de proteger la diversidad de creencias, concepciones del mundo y proyectos de vida. Es decir, de colocar a resguardo del poder político las diferencias que se refieren al ámbito privado. En esta lectura, el centro de gravedad es puesto en la dimensión negativa de los derechos, de protección de la expresión singular de las ideas y formas de vivir. Sin embargo, en términos amplios, la concepción pluralista de la democracia que se propone apunta más bien a la función positiva de la opinión pública, a su valor político.

Lo que pone por delante es que las voces disidentes, no solamente sean protegidas, sino además se les preste atención genuina, para que contribuyan a redefinir el significado de lo público. Nadie se puede apropiar de dicho significado. En este sentido, lo fundamental es la contribución única que cualquiera pueda hacer a la opinión pública.

21 John Rawls, La justicia como equidad. Una reformulación, Barcelona, Paidós, 2002. 
También en esta óptica estrictamente política, y no sólo desde un enfoque de justicia social, el Caso Yatama versus Nicaragua se distingue del Caso Castañeda Gutman versus México. En la medida que Castañeda es un miembro distinguido de las élites mexicanas, su oposición al régimen político luce menos radical y, por ende, menos apremiante desde un punto de vista prácticomoral (porque no sufre discriminación). En resumen: no toda oferta que se suma al mercado político abona por ese mero hecho a la pluralidad, ni amplía la libertad informativa del público, ni genera auténticas alternativas. Por lo tanto, el régimen debe ser particularmente sensible para visibilizar sobre todo la oposición que lo amenaza y le disputa su hegemonía.

\section{Corte IDH, libertades civiles y democracia representativa}

La Corte IDH ha adoptado una interpretación de ciertos derechos civiles que los vincula directamente con los derechos políticos y la democracia, como las libertades de expresión, reunión y asociación, e incluso también de otros derechos que no parecen estar cerca de la política a primera vista, como la vida y la integridad, pero que salen a la luz cuando se tratan casos de homicidios y desapariciones forzadas de disidentes y opositores políticos ${ }^{22}$.

Este criterio de interpretación "sistémico" alrededor de los derechos políticos es sostenido también por Alberto Dalla Vía ${ }^{23}$. En el fondo de todos estos asuntos lo que está en juego son los derechos y las oportunidades efectivas de constituir una oposición radical al régimen político y al gobierno que pueda poner en riesgo su hegemonía, y que por esta razón se expresa casi siempre por fuera de los partidos políticos mayoritarios. Me refiero, verbigracia, a casos como Escué Zapata versus Colombia; Pacheco León y otros versus Honduras; Cepeda Vargas versus Colombia; o Caso Chitay Nech y otros versus Guatemala, donde el objetivo de los atentados contra la vida y la desaparición forzada de personas fue impedir el ejercicio de los derechos políticos ${ }^{24}$.

En Cepeda Vargas vs. Colombia, la Corte IDH asoció la violación de derechos políticos con la libertad de expresión, reunión y asociación, y enfatizó que estos derechos "son de importancia fundamental dentro del Sistema

\footnotetext{
${ }^{22}$ Sobre este tema véase el Cuadernillo de Jurisprudencia de la Corte Interamericana de Derechos Humanos No. 20. Derechos Políticos, San José, Corte IDH, 2018.

${ }^{23}$ Alberto Ricardo Dalla Vía, "Los derechos políticos en el Sistema Interamericano de Derechos Humanos", en Justicia Electoral. Revista del Tribunal Electoral del Poder Judicial de la Federación, Cuarta Época, vol. 1, núm. 8, 2011, pp. 15-79.

${ }^{24}$ Aunque en la muerte del señor Pacheco no se acreditó responsabilidad directa de los agentes estatales, observa la Corte IDH que el Estado debe disponer medidas para garantizar las condiciones adecuadas para el pleno ejercicio de los derechos y "prevenir afrentas a la vida de una persona por su actividad política". Caso Pacheco León y otros versus Honduras, Sentencia del 15 de noviembre de 2017 , párrafos $155,156,158$
}

Araucaria. Revista Iberoamericana de Filosofia, Política, Humanidades y Relaciones Internacionales, año $23, \mathrm{n}^{\circ} 46$. Primer cuatrimestre de 2021. Pp. 461-482. ISSN 1575-6823 e-ISSN 2340-2199 https://dx.doi.org/10.12795/araucaria.2021.i46.23 
Interamericano por estar estrechamente interrelacionados para posibilitar, en conjunto, el juego democrático"25. El señor Cepeda era comunicador y parlamentario, razón por la que la Corte opta por no escindir sus actividades para determinar cuál fuera la causa de las violaciones: sus publicaciones como comunicador o su militancia política de oposición como líder del Partido Comunista. Lo interesante en este caso, para abonar al enfoque de la política pluralista, es el interés de la Corte de garantizar la libertad de expresión, principalmente de las ideas "que resultan ingratas para el Estado o cualquier sector de la población"26. Por ende, resalta "que las voces de oposición resultan imprescindibles para una sociedad democrática" 27 . Las amenazas del estado hacia Cepeda Vargas se tradujeron en restricciones indebidas a sus derechos políticos, su libre expresión y asociación, "pero también en un quebrantamiento de las reglas del juego democrático" 28 . Siendo un tribunal de derechos humanos, es importante como perspectiva hermenéutica el acento que pone en la participación en el sistema político, más allá del aspecto individual de protección hacia la persona como una inmunidad.

A este caso se debe añadir en el mismo sentido el Caso Chitay Nech y otros vs. Guatemala. En este, la Corte IDH observa un "patrón de hostigamiento contra la población considerada 'enemigo interno', en su mayoría mayas" 29 . En el móvil de la violencia la Corte considera acreditada "la intención del Estado de desarticular toda forma de representación política que atentara a su política de 'Doctrina de Seguridad Nacional' " ${ }_{30}$. El grave problema de la subrepresentación de los pueblos indígenas en situaciones de desigualdad es constatado por la Corte IDH como déficit democrático. La desaparición de Florencio Chitay lo privó del derecho de participar en representación de su comunidad: "resulta irrazonable que siendo la población indígena una de las mayoritarias en Guatemala, la representación indígena, a través de sus líderes, como Florencio Chitay Nech, se vea truncada"31.

Bajo estas luces, no sólo es distinto el caso Castañeda a Yatama por criterios de multiculturalidad, marginación y exclusión, sino también es diferente a casos como Cepeda Vargas o Chitay Nech, por su condición de opositores radicales al régimen, es decir, por razones estrictamente políticas. A juicio de la Corte IDH, Castañeda siempre tuvo a su alcance alternativas fáciles de participación, y nunca estuvo bajo amenaza su integridad física.

Me parece que este es el significado auténtico del término "poliarquía" propuesto por Robert Dahl. Su motivo principal es señalar "las condiciones que

${ }^{25}$ Caso Cepeda Vargas vs. Colombia, Sentencia de 26 de mayo de 2010, párrafo 171.

${ }^{26}$ Ídem, párrafo 172.

27 Ídem, párrafo 173.

${ }_{28}$ Ídem, párrafo 177.

${ }^{29}$ Caso Chitay Nech y otros vs. Guatemala, Sentencia del 25 de mayo de 2010, párrafo 108.

30 Ídem, párrafo 108.

31 Ídem, párrafo 116.

Araucaria. Revista Iberoamericana de Filosofia, Política, Humanidades y Relaciones Internacionales, año $23, \mathrm{n}^{\circ} 46$. Primer cuatrimestre de 2021. Pp. 461-482. ISSN 1575-6823 e-ISSN 2340-2199 https://dx.doi.org/10.12795/araucaria.2021.i46.23 
permiten a la oposición al gobierno organizarse abierta y legalmente en partidos políticos y enfrentarse a él en elecciones libres e imparciales" ${ }^{32}$. El aspecto central de la democratización radica en que el sistema "facilite la oposición, la rivalidad y la competencia entre el gobierno y sus antagonistas" 33 .

Adam Przeworski ha expresado que hay un sentido en el que las elecciones y los sistemas de partido "domestican" a la oposición al procesar pacíficamente los conflictos, pero eso es sólo posible "cuando no hay mucho en juego en ellas y cuando las fuerzas políticas en pugna aprenden mediante la experiencia que no hay tanto en riesgo" 34 .

Siguiendo a Chantal Mouffe, se podría decir que cualquier oposición al gobierno debe ser protegida; pero el sistema político tiene que ser especialmente sensible con la oposición que sea más desafiante ${ }^{35}$; con la que amenaza no solamente las políticas actuales del gobierno en turno, sino incluso las que cuestionan la legitimidad de los procedimientos de la competencia política.

Los casos de la Corte IDH relacionados con derechos políticos como Yatama o Castañeda, y los de libertades civiles, revelan una idea de democracia representativa consistente con la CDI y con las concepciones liberales que han prevalecido en la ciencia política y en las constituciones de la región latinoamericana en los últimos años, tras la llamada tercera ola de transiciones democratizadoras. Resulta pertinente comprender la democracia con perspectiva diacrónica para señalar los valores que la han hecho posible, así como los aterrizajes institucionales que la propician o la entorpecen. Sobre todo en el contexto actual de crisis de legitimidad, con amenazas a la estabilidad de regímenes electos democráticamente.

\section{La dimensión política de (todos) los derechos humanos: consulta previa y acceso a la justicia.}

Los casos de derechos de los pueblos indígenas y tribales tratados por la Corte IDH han puesto énfasis en su condición de desventaja. De modo especial se han destacado problemas de discriminación, marginación y pobreza. Sin embargo, en el Caso Yatama vs. Nicaragua se reconocen específicamente derechos políticos de participar en forma proporcional a su población en asuntos públicos, de acuerdo con sus tradiciones, usos y costumbres. El resto

\footnotetext{
${ }^{32}$ Robert Dahl, La poliarquía. Participación y oposición, op. cit., p. 13.

33 Ídem, p. 13.

34 Adam Przeworski, ¿Por qué tomarse la molestia de hacer elecciones? Pequeño manual para entender el funcionamiento de una democracia, Buenos Aires, Siglo XXI Editores Argentina, 2019, cap. 10 (ed. Kindle)

${ }^{35}$ Chantal Mouffe, Agonística. Pensar el mundo políticamente, Ciudad de México, FCE, 2014.
} 
de asuntos fueron juzgados como daños a otro tipo de derechos: propiedad, vida digna, libertad de conciencia y religión, integridad, uso de idioma, etc ${ }^{36}$.

En este apartado retomo una idea de Rodolfo Stavenhagen, según quien la mayor parte de demandas indígenas no son de redistribución económica o de reconocimiento cultural, sino políticas: tienen que ver con asuntos de ciudadanía y de derechos humanos ${ }^{37}$.

Desde esta perspectiva, en relación con el tema de la democracia, los casos relacionados con consulta previa a pueblos indígenas y tribales de la región, ganarían una comprensión diferente. Se degrada el estatus ciudadano de las personas y pueblos indígenas cuando se asimilan sus derechos políticos para participar en los asuntos públicos que les conciernen, que son derechospoder constitutivos, con otros derechos como la propiedad sobre sus tierras, que son derechos-inmunidad. Aunque éstos sean bien importantes, admiten ser disfrutados en forma pasiva.

Si se mira la consulta con perspectiva amplia y referida al sistema político, la cuestión democrática resulta ineludible. Porque las consultas tratan de los derechos de autonomía y autodeterminación de los pueblos, bajo el entendimiento de que sus integrantes están subrepresentados y, en este sentido, que quizás hayan tenido menos oportunidades de hacer escuchar sus voces y visibilizar sus posiciones en un escenario de competencia política regular. $\mathrm{Su}$ desventaja como minorías, su insularidad y sus diferencias justifican adicionar un procedimiento de carácter deliberativo al marco habitual de las democracias representativas. Su objetivo sería retardar las decisiones, pausarlas, para tomarse en serio todas y cada una de las razones expuestas por personas y grupos cuya exclusión se presume desde un punto de vista heurístico.

Llama la atención que cuando las personas, pueblos y comunidades indígenas hacen una demanda relativa a sus territorios ancestrales, les sean atribuidas casi siempre conexiones "espirituales" con esos territorios. Su cosmovisión e identidades culturales son puestas por delante. Aunque este trato sea bienintencionado, disimula un menosprecio por las demandas indígenas tal como son hechas por los propios pueblos, a las que en consecuencia no se toman en serio. Esto ocurre, verbigracia, en el Caso Comunidad Indígena Yakye Axa vs. Paraguay, Caso Pueblo Indígena Kichwa de Sarayaku vs. Ecuador, Caso Mayagna (Sumo) Awas Tingni vs. Nicaragua y Caso Comunidad Garifuna de Punta Piedra y sus Miembros vs Honduras. En este se lee: "Para las comunidades indígenas la relación con la tierra no es meramente una cuestión de posesión y producción sino un elemento material y espiritual del que deben

\footnotetext{
${ }^{36}$ Karla Quintana Osuna y Juan Jesús Góngora Maas, Los derechos de los pueblos indigenas y tribales en los Sistemas de Derechos Humanos, México, UNAM-CNDH, 2017.

${ }^{37}$ Rodolfo Stavenhagen, “Asimilación o pluralismo? El fin de la asimilación”, en Memoria del Primer Encuentro Internacional sobre Filosofía de la Cultura y Multiculturalismo, Campeche, 2004, pp. 67-77.
}

Araucaria. Revista Iberoamericana de Filosofía, Política, Humanidades y Relaciones Internacionales, año $23, \mathrm{n}^{\circ} 46$. Primer cuatrimestre de 2021. Pp. 461-482. ISSN 1575-6823 e-ISSN 2340-2199 https://dx.doi.org/10.12795/araucaria.2021.i46.23 
gozar plenamente, inclusive para preservar su legado cultural y transmitirlo a las generaciones futuras" 38 .

Para la Corte IDH en estos casos lo relevante, en relación con el derecho a la consulta y la consecuente afectación a las propiedades de las comunidades y pueblos, es el derecho a la identidad cultural; es decir, la dimensión del reconocimiento. Pero esto es problemático, porque en la mayoría de los casos las comunidades y pueblos reclaman derechos y libertades fundamentales: no ser despojados del uso, disfrute, posesión o propiedad de sus territorios. De igual modo, con el derecho a la consulta, en esta interpretación democrática, se demanda el poder de ejercitar sus derechos políticos de autogobierno y autodeterminación. Así entendido, la consulta conecta con el acceso a la justicia como un derecho "llave" para reclamar cualquier derecho, un instrumento que se propone maximizar la participación inclusiva y la oposición plural de un sector de la población que, de otra manera, la tendría vedada.

Laura Clérico y Martín Aldao ${ }^{39}$ han ensayado aplicar la propuesta de Fraser de pensar la justicia en diferentes dimensiones: económica, cultural, y política en relación con el Sistema Interamericano de Derechos Humanos. Recuérdese que Fraser planteó la necesidad de complementar la redistribución con el reconocimiento, al tenor de los debates generados por feminismo y multiculturalismo, pero luego incluyó la dimensión directamente política de la justicia asociándola con la representación y desarrollándola en términos de paridad participativa.

Se puede pensar la consulta previa como un mecanismo de paridad participativa, que se justifica como una cuestión al mismo tiempo redistributiva (por tratar de grupos pobres y marginales) como de reconocimiento (por su distinta identidad frente a la sociedad hegemónica). Pero bajo esta lógica, no es que redistribución o reconocimiento sean medios para lograr la igualdad participativa, sino lo contrario: se debe siempre garantizar condiciones equitativas para que todas las personas y colectivos puedan participar eficazmente.

El problema de la participación de personas y grupos desaventajados aparenta vicios de circularidad. Sin embargo, la respuesta no es demasiado complicada en términos normativos. Con independencia de la vulnerabilidad de las personas y de los déficits participativos que se les puedan imputar, no se puede prescindir de lo que alguien tenga que decir sobre las decisiones que le

\footnotetext{
${ }^{38}$ Caso Comunidad Garífuna de Punta Piedra y sus Miembros vs. Honduras, Sentencia de 8 de octubre de 2015, párrafo 166. La misma afirmación está presente en Caso Mayagna (Sumo) Awas Tingni vs. Nicaragua, párrafo 149 y en Caso Comunidad Indígena Xákmok Kásek vs. Paraguay, Sentencia de 24 de agosto de 2010, párrafo 86.

${ }^{39}$ Laura Clérico y Martín Aldao, "De la inclusión como igualdad en clave de redistribución y reconocimiento. Rasgos, potencialidades y desafíos para el Derecho Constitucional Interamericano", en Armin Von Bogdandy, Héctor Fix Fierro, Mariela Morales Antoniazzi (coords.), Ius Constitutionale Commune en América Latina, México, UNAM, 2014, p. 221.
} 
afectan: "el debate democrático no debe ser un debate 'sobre' los ciudadanos, sino un debate 'con' ellos"

El acceso a la justicia como derecho con una dimensión políticademocrática, como aquí se interpreta, se traduce en un poder de la ciudadanía en una connotación incluyente que toma en consideración a personas y pueblos indígenas. La Corte ha asumido esta interpretación en el Caso Pueblos Kaliña y Lokono vs. Surinam ${ }^{41}$

\begin{abstract}
$\mathrm{Al}$ respecto, la Corte recuerda que el artículo 23 de la Convención Americana dispone el deber de gozar de los derechos y oportunidades "de participar en la dirección de los asuntos públicos...”. En este sentido, la participación en la conservación del medio ambiente para las comunidades indígenas resulta no sólo en un asunto de interés público sino parte del ejercicio de su derecho como pueblos indígenas a participar en la adopción de decisiones en las cuestiones que afectan sus derechos, de conformidad con sus procedimientos e instituciones ${ }^{42}$.
\end{abstract}

Lo relevante de esta sentencia respecto de otras anteriores sobre estos temas es el vínculo expreso que la Corte IDH estipula entre el derecho de propiedad colectiva, la consulta y los derechos políticos señalados en el artículo 23 de la Convención Americana de Derechos Humanos. Que las personas, pueblos y comunidades indígenas no cuenten con medios de control sobre sus territorios viola sus derechos de propiedad, identidad cultural y derechos políticos ${ }^{43}$.

El sentido de la sentencia es original porque en un asunto anterior, el Caso Pueblo Indígena Kichwa de Sarayaku vs. Ecuador, pese a que la Comisión IDH y los representantes alegaron también una violación a dicho artículo 23 de la Convención, relativo a los derechos políticos, e indicaron como cuestión relevante el "control democrático de la gestión estatal respecto de las actividades de exploración y explotación de los recursos naturales en el territorio de las comunidades indígenas, un asunto evidente de interés público"; no obstante la Corte acotó su decisión a violaciones relativas a la propiedad comunal, la consulta y la identidad cultural, y "no se pronuncia sobre la alegada violación de aquellas normas" 44 . Esta sentencia abre una vía fértil para interpretar mejor este tipo de casos sobre consulta previa con un enfoque de derechos políticos, que sería coherente con la noción de democracia liberal e igualitaria.

\footnotetext{
40 Ídem, p. 261.

${ }^{41}$ Caso Pueblos Kaliña y Lokono vs. Surinam, Sentencia del 25 de noviembre de 2015.

42 Ídem, párrafo 196.

43 Ídem, párrafo 197.

${ }^{44}$ Caso Pueblo Indígena Kichwa de Sarayaku vs. Ecuador, Sentencia del 27 de junio de 2012.
} 


\section{A modo de conclusión}

Este trabajo propone una perspectiva para analizar la idea de democracia que está presente en el Sistema Interamericano de Protección de los Derechos Humanos. Tenemos un modelo de democracia representativa, en la que destaca el acceso al poder mediante elecciones periódicas, libres y justas. De tal manera que se deduce su carácter competitivo, pluralista y liberal. En la teoría política Robert Dahl ha propuesto una forma de comprender este modelo, que denomina "poliarquía". Ésta proyecta dos principios que se han querido subrayar en la lectura de sentencias de la Corte IDH: la participación de todas las personas y grupos, que expresa la dimensión igualitaria de la democracia; y las garantías par la oposición plural, incluso la más radical: desobediencia civil, objeción de conciencia, resistencia y protesta, que expresan su dimensión liberal.

En virtud de la normas de interpretación de emplear una hermenéutica integral que no excluya los derechos y las garantías que derivan "de la forma representativa de gobierno", conviene explicitar la responsabilidad y el papel político de la Corte IDH, con independencia de la materia de las demandas; y más allá de que éstas se refieran estrictamente a derechos políticos. Porque, según lo dicho, todos los derechos poseen una dimensión política que se revela con claridad en el derecho de acceso a la justicia como un derecho poder o de participación.

En el trabajo se llamó la atención sobre las condiciones de desventaja de determinadas personas y grupos. Esto no significa que los principios democráticos importen exclusivamente a los grupos peor situados. Sin embargo, su situación permite apreciar en los casos prácticos cuál pueda ser el sentido de las ideas de participación y oposición que deban servir de pautas de interpretación.

Hay que tener presente que ambos sistemas, el de protección de los derechos y el de la democracia, se echan a andar en momentos de conflicto y de desarreglos. Por ende parece mejor como estrategia heurística hacer visible las posiciones relativas de los agentes en litis para juzgar su capacidad de participar, comunicar sus demandas en forma efectiva y recibir una respuesta institucional justificada. El derecho de acceso a la justicia, siempre que sea efectivo, confiere a todas las personas un estatus libre e igual.

Por otra parte, la estrategia de mirar conjuntamente derechos y democracia conduce a leer la infinidad de reclamos en la esfera pública como expresión del pluralismo y, en este sentido, a juzgarlos con un propósito deliberado de inclusión y acomodamiento en la mayor medida posible, por extravagantes que puedan parecer a primera vista. De manera especial se deben proteger las voces opositoras al sistema político; las críticas de quienes disienten o son afectados por ciertas políticas; o de quienes han estado permanentemente excluidos. Tal 
vez sean necesarios ejercicios de traducción intercultural, o ajustes procesales como la redistribución de cargas argumentativas y probatorias a favor de ciertas posiciones, flexibilizando procedimientos para equiparar las oportunidades de las partes -la igualdad de armas-. En esto consistiría la dimensión política de la libertad como horizonte hermenéutico de los jueces.

De todos modos, esta propuesta de pautas interpretativas de la democracia y los derechos humanos no es la única plausible y puede convivir con otras en paralelo. Su finalidad y sus alcances prácticos son bien específicos: tiene que ver con comprender la responsabilidad política de la judicatura en la tarea de apuntalar el régimen democrático favoreciendo los valores de igualdad y libertad que le subyacen. Dichos valores aterrizan en los principios de igual participación incluyente y de oposición plural. Habrá un sinnúmero de asuntos que no tengan que ver con el régimen político, y sin embargo, todos implican agencia y capacidad de participación en los sujetos que dirigen sus demandas a los tribunales. 


\section{Referencias bibliográficas:}

Alexy, Robert, "Los derechos fundamentales en el Estado constitucional democrático", en Miguel Carbonell (ed.), Neoconstitucionalismo(s), Madrid, Trotta, 2009, pp. 31-47.

Bogdandy, Armin von e Ingo Venzke, ¿En nombre de quién? Una teoría del derecho público sobre la actividad judicial internacional, Bogotá, Universidad Externado de Colombia, 2016.

Clérico, Laura, y Martín Aldao, "De la inclusión como igualdad en clave de redistribución y reconocimiento. Rasgos, potencialidades y desafíos para el Derecho Constitucional Interamericano", en Armin Von Bogdandy, Héctor Fix Fierro, Mariela Morales Antoniazzi (coords.), Ius Constitutionale Commune en América Latina, México, UNAM, 2014, pp. 219-262.

Corte IDH, Cuadernillo de Jurisprudencia de la Corte Interamericana de Derechos Humanos No. 20. Derechos Politicos, San José, Corte IDH, 2018.

Cuéllar M., Roberto y José Thompson, "Presentación", en VVAA, Construyendo las condiciones de equidad en los procesos electorales, Serie Cuadernos de Capel No. 57, San Jose, IIDH, 2012.

Dahl, Robert, La poliarquía. Participación y oposición, Madrid, Tecnos, 1989. Dalla Vía, Ricardo, "Los derechos políticos en el Sistema Interamericano de Derechos Humanos", en Justicia Electoral. Revista del Tribunal Electoral del Poder Judicial de la Federación, Cuarta Época, vol. 1, núm. 8, 2011, pp. 15-79.

Ferrajoli, Luigi, Los fundamentos de los derechos fundamentales, Madrid, Trotta, 2001.

Fraser, Nancy, Escalas de justicia, Barcelona, Herder, 2008.

Gargarella, Roberto, (comp.), Por una justicia dialógica. El Poder Judicial como promotor de la deliberación democrática, Buenos Aires, Siglo XXI, 2014.

Habermas, Jürgen, "La desobediencia civil. Piedra de toque del Estado democrático de derecho", Ensayos políticos, Barcelona, Península, 2000, pp. 51-71.

Hart Ely, John, Democracy and Distrust: A Theory of Judicial Review, Cambridge, Mass., Harvard University Press, 1980.

Islas-Colín, Alfredo y Alejandra Díaz Alvarado, "El derecho de acceso a la justicia en el Sistema Interamericano de Protección de Derechos Humanos: construcción doctrinal y jurisprudencial", Prospectiva jurídica, México, UAEM, año 7, número 14, julio-diciembre 2016, p. 47. 
Lissidini, Alicia, Yanina Welp y Daniel Zovatto (comps.), Democracias en movimiento. Mecanismos de democracia directa y participativa en América Latina, Ciudad de México, UNAM, 2014.

Merino, Mauricio, La transición votada, Ciudad de México, FCE, 2003.

Meza Salazar, Sergio, "La democracia y el Sistema Interamericano: de la Carta de la OEA a la Carta Democrática Interamericana”, Agenda Internacional, Año VII, No. 16, 2002, pp. 97-122.

Mouffe, Chantal, Agonística. Pensar el mundo políticamente, Ciudad de México, FCE, 2014.

Nikken, Pedro, "Análisis de las definiciones conceptuales básicas para la aplicación de los mecanismos de defensa colectiva de la democracia previstos en la Carta Democrática Interamericana”, Revista IIDH, vol. 43, 2006, pp. 13-53.

O’Donnell, Guillermo, Democracia, agencia y estado. Teoría con intención comparativa, Buenos Aires, Prometeo Libros, 2010.

Przeworski, Adam, ¿Por qué tomarse la molestia de hacer elecciones? Pequeño manual para entender el funcionamiento de una democracia, Buenos Aires, Siglo XXI Editores Argentina, 2019, cap. 10 (ed. Kindle)

Quintana Osuna, Karla, y Juan Jesús Góngora Maas, Los derechos de los pueblos indígenas y tribales en los Sistemas de Derechos Humanos, México, UNAM-CNDH, 2017.

Rawls, John, El liberalismo político, Barcelona, Crítica, 1996.

Rawls, John, La justicia como equidad. Una reformulación, Barcelona, Paidós, 2002

Roemer, John, Equality of Opportunity, Cambridge, Harvard University Press, 1998.

Saba, Roberto, Más allá de la igualdad formal ante la ley ¿Qué les debe el Estado a los grupos desaventajados?, Buenos Aires, Siglo XXI, 2016.

Schumpeter, Joseph A., Capitalismo, socialismo y democracia (vols. I y II), Barcelona, Folio, 1996.

Stavenhagen, Rodolfo, “Asimilación o pluralismo? El fin de la asimilación”, en Memoria del Primer Encuentro Internacional sobre Filosofía de la Cultura y Multiculturalismo, Campeche, 2004, pp. 67-77.

Trindade, Cançado, "El derecho de acceso a la justicia internacional y las condiciones para su realización en el sistema interamericano de protección de los derechos humanos", Revista IIDH, vol. 37, 2003, pp. 53-83. 